\title{
A POLÍTICA DE DESENVOLVIMENTO DA INDÚSTRIA FARMACÊUTICA BRASILEIRA DE 2003 A $2014^{1}$
}

\author{
Ricardo Lobato Torres \\ Departamento Acadêmico de Gestão e Economia (DAGEE) \\ Universidade Tecnológica Federal do Paraná (UTFPR)
}

\begin{abstract}
RESUMO
$\mathrm{O}$ artigo discute as mudanças institucionais promovidas pelo governo federal a fim de viabilizar uma política industrial para a indústria farmacêutica a partir de 2003. As políticas industriais da PITCE de 2004, PDP de 2008 e PBM de 2011, estabeleceram o chamado complexo econômicoindustrial da saúde como área prioritária de atuação. O governo lançou uma série de medidas para promover o desenvolvimento industrial, como a oferta de crédito subsidiado, isenções fiscais, estímulos à interação universidade-empresa, subvenção econômica, investimento público e, principalmente, o uso do poder de compra do Estado, através das demandas do SUS, para promover uma política de parcerias público-privadas a fim de financiar um processo de transferência de tecnologia para a produção local de medicamentos estratégicos, como antirretrovirais, oncológicos e produtos biológicos. As Parcerias para o Desenvolvimento Produtivo (PDPs) do Ministério da Saúde, iniciadas em 2008, representam o ápice da política industrial orientada à indústria farmacêutica. Através de uma revisão de mudanças institucionais, com ênfase na legislação, o objetivo desse artigo é demonstrar a orquestração de interesses e mudanças no marco regulatório promovidas pelo governo federal para poder aplicar uma política discricionária de capacitação tecnológica dos laboratórios públicos e privados brasileiros, mediante o uso de poder de compra do Estado e a inclusão dos laboratórios estrangeiros nesse processo.
\end{abstract}

Palavras-chaves: política industrial, indústria farmacêutica, política de desenvolvimento produtivo.

\begin{abstract}
The article discusses the institutional changes promoted by the federal government in order to facilitate an industrial policy for the pharmaceutical industry since 2003. The industrial policies like 2004's PITCE, PDP's 2008 and PBM's 2011, established the so-called economic-industrial complex health as a priority area of action. The government launched a series of measures to promote industrial development, such as subsidized credit supply, tax exemptions, incentives for universityindustry interaction, economic support, public investment, and especially the use of state purchasing power through demands of the SUS, to promote a policy of public-private partnerships to fund a technology transfer process for the local production of strategic medicines, such as antiretroviral drugs, oncological and biological products. Partnerships for Productive Development (PDPs) of the Ministry of Health, launched in 2008, represents the culmination of industrial policy geared to the pharmaceutical industry. Through a review of institutional changes, with emphasis on legislation, the aim of this article is to demonstrate the orchestration of interests and changes in the regulatory framework promoted by the federal government in order to apply a discretionary policy to build technological capabilities in national public and private laboratories, by using purchasing power of the state and including foreign laboratories in that process.
\end{abstract}

Keywords: industrial policy, pharmaceutical industry, productive development policy.

Área Temática: Área 8 - Políticas Industriais e Comerciais

1 Essa pesquisa foi apoiada pelo Conselho Nacional de Desenvolvimento Científico e Tecnológico (CNPq), Edital N. ${ }^{\circ}$ 41/2013, e pela Fundação Carlos Chagas Filho de Amparo à Pesquisa do Estado do Rio de Janeiro (FAPERJ), Edital N. ${ }^{\circ} 01 / 2013$. 
Códigos JEL: L52, L65, O38. 


\section{Introdução}

A partir de 2004, o governo federal brasileiro adotou uma política industrial mais ativa, com o lançamento da Política Industrial, Tecnológica e de Comércio Exterior (PITCE). Dentre os eixos de ações previstas, estava o estímulo ao desenvolvimento de setores considerados estratégicos, sendo a indústria de fármacos e medicamentos uma delas. Em consonância com a PITCE, o Banco Nacional de Desenvolvimento Econômico e Social (BNDES) lançou neste mesmo ano o Programa de Apoio ao Desenvolvimento do Complexo Industrial da Saúde (PROFARMA), para financiamento de projetos empresariais, visando principalmente o adensamento da cadeia produtiva da indústria farmacêutica (PIERONI, 2014).

Em 2008, com a revisão da política industrial do governo federal, foi lançada a Política de Desenvolvimento Produtivo (PDP), que ampliou o leque de setores considerados estratégicos. No caso específico da indústria farmacêutica, houve uma reestruturação dos esforços no sentido de promover o desenvolvimento de todo o complexo econômico-industrial da saúde (CEIS), o que inclui a produção de equipamentos médicos e hospitalares e a prestação de outros serviços de saúde (GADELHA, 2012). Assim, já em 2007, o BNDES lançava a segunda fase do PROFARMA, que visava o financiamento de investimentos produtivos de empresas de todo o CEIS (PIERONI, 2014).

Além disso, iniciou-se em 2008 uma série de parcerias público-privadas no âmbito do Ministério da Saúde - denominadas de Parcerias para o Desenvolvimento Produtivo (PDPs) - para a produção local de medicamentos visando baratear a aquisição de medicamentos estratégicos para o Sistema Único de Saúde (SUS), como é o caso dos antirretrovirais, e reduzir o défice comercial da indústria farmacêutica brasileira. Toda essa estratégia de fortalecimento do CEIS foi articulada pelo Grupo Executivo do Complexo Industrial da Saúde (GECIS), instituído neste mesmo ano. O GECIS é coordenado pelo Ministério da Saúde, mas trata-se de um conselho formado por representantes de vários órgãos da administração pública direta e indireta, como outros ministérios, agências governamentais e fundações (BRASIL, 2008).

Com o Plano Brasil Maior (PMB), lançado em 2011, houve um reforço das políticas industriais e tecnológicas direcionadas ao CEIS. Incluiu-se, por exemplo, o CEIS na Estratégia Nacional de Ciência, Tecnologia e Inovação 2012-2015 (MINISTÉRIO DA CIÊNCIA, TECNOLOGIA E INOVAÇÃO, 2012). Uma ação concreta dessa estratégia se traduziu no lançamento do Programa Inova Saúde da Financiadora de Estudos e Projetos (FINEP), cujo foco foi a provisão de subvenção econômica para empresas públicas e privadas no país com propostas de projetos de inovação tecnológica em áreas relacionadas à saúde, com destaque para biofármacos, farmoquímicos e medicamentos (FINEP, 2013). Destaca-se, ainda, que em 2013 o BNDES lançou a terceira fase do PROFARMA, visando o financiamento de projetos empresariais de biotecnologia farmacêutica e biomédica (PIERONI, 2014).

Assim, com a retomada da política industrial, o Brasil tem tentado orquestrar diversas políticas visando principalmente reduzir a dependência das importações, facilitar o acesso aos medicamentos no SUS e minimizar o défice comercial do setor. A ação mais incisiva nesse sentido são as PDPs, organizadas pelo GECIS, que visam capacitar os laboratórios farmacêuticos públicos e privados nacionais a produzir medicamentos de maior complexidade tecnológica, através de acordos de transferência de tecnologia junto aos laboratórios multinacionais. Grosso modo, trata-se de uma política que utiliza o poder de compra do Estado para criar um estímulo ao investimento por parte dos laboratórios nacionais ao mesmo tempo em que "reparte" o mercado público entre três atores: o laboratório público da rede oficial (chamados de laboratórios farmacêuticos oficiais LFO), o laboratório privado nacional (leia-se empresas cujo controle do capital é brasileiro - LPN) e o laboratório farmacêutico multinacional (LFM).

No entanto, o uso das compras públicas como uma política discricionária encontrava vários entraves estabelecidos pela "Lei de Licitações” (Lei 8.666, de 21/06/1993). Para viabilizar o uso do poder de compra do Estado como um instrumento de política industrial, não só no caso do CEIS, mas também em outras frentes das políticas supracitadas, uma série de alterações na legislação se fizeram necessárias. Alguns avanços foram obtidos, como a margem de preferência para micro e 
pequenas empresas (em sua maioria da capital nacional) e em processos de transferência de tecnologia envolvendo empresas nacionais.

Assim, o objetivo deste trabalho é identificar as mudanças institucionais (que incluem as mudanças legais) no âmbito do governo federal e discutir sua importância para viabilizar uma política industrial de transferência tecnológica para o desenvolvimento de uma indústria nacional de produção de medicamentos estratégicos, com ênfase nos medicamentos biológicos, que tem um peso elevado no orçamento do SUS e que são tecnologicamente mais complexos, o que exige um grande esforço de aprendizado na indústria brasileira.

Além desta introdução, o artigo está estruturado em mais quatro seções. Na seção dois são apresentadas a organização e os incentivos econômicos das PDPs, que é o foco da análise desta pesquisa. Na terceira seção, descreve-se brevemente o referencial teórico e analítico, bem como a metodologia empregada na pesquisa. A quarta seção demonstra os resultados da pesquisa e faz uma breve discussão sobre os avanços e os limites da política em termos da sua capacidade de promover o desenvolvimento industrial e tecnológico da indústria farmacêutica brasileira. Por fim, a quinta e última seção traz as considerações finais da pesquisa.

\section{A estratégia de transferência de tecnologia e produção local das PDPs}

Até 2014, havia 104 PDPs firmadas, sendo que as propostas previam, ao término do período de 10 anos, a produção local do insumo farmacêutico ativo (IFA) pelo parceiro privado (preferencialmente um laboratório de capital nacional, mas não obrigatoriamente) e formulação pelo parceiro público. Dentre esses acordos, 25 eram específicos para produtos biológicos, firmados até 2013. Segundo dados do Ministério da Saúde, a compra de medicamentos biológicos totaliza pouco mais de $2 \%$ da quantidade adquirida pelo SUS, mas que representa mais $40 \%$ dos gastos, o que justifica o foco da análise desta pesquisa em tais medicamentos (MINISTÉRIO DA SAÚDE, 2009).

A política das PDPs estabeleceu um processo de transferência de tecnologia em que os detentores da tecnologia de produção, sejam os inovadores ou os produtores de biossimilares, têm o compromisso de transferir toda a tecnologia de produção para os laboratórios nacionais. Não necessariamente um único laboratório brasileiro tem de dar conta de todo o processo produtivo. Em alguns casos, geralmente um LPN, será responsável pela produção do IFA, enquanto o LFO ficará encarregado da formulação final dos medicamentos e da distribuição junto ao Ministério da Saúde. Frise-se que deve haver um parceiro público, isto é, um LFO. Como ente da administração pública indireta, o LFO tem a prerrogativa de poder fornecer medicamentos ao SUS com dispensa de licitação. Assim, o principal objetivo da política é nacionalizar a produção de produtos estratégicos e, com isso, baratear o custo de aquisição desses produtos no âmbito do SUS.

O Ministério da Saúde estabeleceu um prazo de até dez anos para que ocorra a transferência completa de tecnologia. Nesse ínterim, os laboratórios nacionais podem integrar verticalmente a produção por etapas, sendo a etapa inicial a mais simples, embalagem secundária e distribuição. Mais importante do que isso é que, com a garantia de compra por parte do setor público sem a necessidade de licitação, os transferidores de tecnologias serão, na verdade, vendedores dos produtos, sendo os laboratórios nacionais, em especial os LFOs, meros revendedores nessa fase inicial. Esse mecanismo cria um mercado público cativo e indireto para os parceiros detentores da tecnologia (leia-se LFMs) e funciona como um forte incentivo à transferência de tecnologia (BRASIL, 2014).

Outro aspecto importante a considerar é que, no caso dos inovadores (novamente um LFM), cuja patente já expirou ou está prestes a expirar, as PDPs podem representar uma sobrevida de até dez anos no mercado público. Isso, no entanto, não significa manutenção do volume de lucros no mercado brasileiro, porque há, em contrapartida à garantia de compra, a exigência de redução gradativa dos preços. Na verdade, já no início do projeto, há uma negociação do preço de entrada dos produtos-alvo das PDPs, intermediado pela Câmara de Regulação do Mercado de Medicamentos (CMED), sendo estes abaixo dos preços vigentes atualmente no mercado. Já para os produtores de biossimilares, as PDPs representam uma janela de oportunidade para ingressar no 
mercado brasileiro. Analisando a lista das PDPs aprovadas para produtos biológicos, verifica-se que a maioria dos parceiros estrangeiros não inovadores são empresas que ainda não atuam no Brasil ${ }^{2}$.

Para os LFOs, porém, há um importante percalço: para um mesmo produto existe a possibilidade de que mais de um LFO tenha projeto aprovado no Ministério da Saúde, o que significaria ter de repartir o mercado. De fato, já existem produtos em que há projetos aprovados para mais de um laboratório nacional (leia-se o LFO e seu parceiro LPN). Assim, quem chegar primeiro leva todo mercado, temporariamente, até que os outros cheguem, e assim, divide-se o mercado. A principal implicação disso é a viabilidade econômica dos investimentos necessários, tanto em estrutura fixa, quanto em pessoal e capital de giro.

Segundo informativos do Ministério da Saúde, os LFOs foram contemplados na estratégia de capacitação tecnológica e receberam investimentos crescentes a partir de 2003. No período de 2000 a 2011, foram investidos R\$ 512 milhões. Com a instituição do Programa para o Desenvolvimento do Complexo Industrial da Saúde (PROCIS), em 2012, que dentre outros objetivos, busca o fortalecimento dos produtores públicos, previu-se que os laboratórios receberiam R\$ 1 bilhão em investimentos entre 2012 e 2015, sendo que R\$ 250 milhões já foram realizados em 2012. Tal medida foi implementada para tornar factível a estratégia de incorporação tecnológica das PDPs pelos produtores públicos (GADELHA, 2013; MINISTÉRIO DA SAÚDE, 2012).

Porém, nem todas as parcerias preveem o repasse de dinheiro público aos LFOs para realização dos investimentos em capacidade produtiva. Isso significa que muitos terão de encontrar outras fontes de recursos. Considerando o caso dos LPNs, esta questão é ainda mais crucial, já que terão de investir com recursos próprios ou, quando muito, com financiamento subsidiado via BNDES ou outro órgão de fomento. Por outro lado, "fatiar" o mercado pode representar repartição de receitas e, com isso, aumenta-se o risco de inviabilidade econômica dos projetos. Isso porque só a construção de uma unidade produtiva aderente às boas práticas de fabricação (BPF) e a compra dos equipamentos podem representar um investimento da ordem de R\$ 100 milhões. Assim, mais importante do que obter os recursos para investir, é recuperá-lo. Se as PDPs não gerarem recursos para os laboratórios (públicos e privados), perde-se a razão econômica para apostar no projeto.

Logo, se por um lado há um forte incentivo econômico para transferidores e receptores de tecnologia, por outro, há um considerável risco de inviabilidade econômica dos projetos. Outro risco não explícito é o fato de que, no decorrer dos dez anos, os produtos biológicos das PDPs, que já possuem pelo menos vinte anos de existência (prazo de vigência da patente), podem se tornar obsoletos, no sentido de que medicamentos mais eficientes ou mesmo tratamentos por outros paradigmas tecnológicos, como é o caso da terapia gênica, venham a surgir e tomar o lugar de tais produtos. Assim, a capacidade absortiva e a intensidade dos esforços para aprender a nova tecnologia de cada parceiro para fabricar e distribuir os produtos é fundamental para o sucesso econômico das PDPs, porque quanto maior a morosidade na implementação dos projetos, maior o risco de obsolescência dos produtos-alvo.

\section{Referencial teórico e analítico e metodologia de pesquisa}

Embora não se apresente aqui uma revisão exaustiva da economia institucional, convém destacar, ainda que brevemente, as dimensões das instituições que servirão de plano de fundo da análise que se segue na próxima seção do artigo. A definição de instituições, conforme Hodgson (2006), contempla o conjunto de estruturas explícitas e implícitas que orientam as interações sociais. Entre essas estruturas estão a linguagem, os costumes, as leis, as normas, as organizações e assim por diante. As instituições cumprem um duplo papel de restringir e de permitir determinados comportamentos na vida em sociedade. Trata-se, portanto, de um conceito bastante abrangente e controverso na literatura.

Optou-se aqui por uma análise institucionalista mais estrita, no sentido de que o objeto de

2

A lista das PDPs aprovadas pode ser consultada no site do Ministério da Saúde, disponível em: http://portalsaude.saude.gov.br/index.php/o-ministerio/principal/leia-mais-o-ministerio/581-sctie-raiz/deciis/l2deciis/12090-parceria-para-o-desenvolvimento-produtivo-pdp . Acesso em 29 jun. 2016. 
análise se resume às normas legais no âmbito do governo federal, isto é, leis, decretos e portarias. Além disso, duas dimensões específicas das instituições são de principal interesse na pesquisa: instituições enquanto permissões e instituições enquanto indutoras de comportamento.

Não apenas interessa a conotação dada por North (1990), de que as instituições determinam o desempenho econômico, mas também no sentido de que elas criam os incentivos à ação econômica, ou seja, na criação de uma estrutura de incentivo e de confiança nas empresas públicas e privadas. No caso específico da política industrial orientada à indústria farmacêutica brasileira, as mudanças institucionais discutidas na próxima seção

Em relação à metodologia da pesquisa, os dados para análise da política industrial foram obtidos a partir de uma revisão histórica de documentos oficiais do Ministério da Saúde e do governo federal, todos relacionados direta ou indiretamente às PDPs. Trata-se, essencialmente, de dados qualitativos, envolvendo leis, decretos, portarias, normas e acordo contratuais que regulamentam as PDPs. O período de análise fica restrito ao período de 2004 a 2014, que data o início da política industrial mais incisiva pelo governo federal até o ano de 2014, quando data a última portaria do Ministério da Saúde que regulamenta as PDPs. Registre-se, porém, que outras alterações normativas ocorreram após esse período, e que certamente merecem análise, mas que por conveniência foram desconsiderados pelo autor no presente trabalho. O levantamento das alterações legais foram por consultadas nos websites dos Ministérios, da Presidência e do Senado.

\section{Resultados e Discussão}

O Quadro 1 apresenta a lista de medidas políticas adotadas a partir de 2004 para tentar viabilizar uma nova onda de industrialização e capacitação tecnológica na indústria farmacêutica brasileira. As mudanças institucionais não esgotam, obviamente, todas as mudanças ocorridas nos últimos 15 anos, no que diz respeito às iniciativas de criar políticas industriais discricionárias. No entanto, consideram-se os eventos listados suficientes para ilustrar os caminhos percorridos para viabilizar um processo de transferência de tecnologia na indústria farmacêutica brasileira.

As mudanças institucionais foram apresentadas em ordem cronológica. Como já mencionado na introdução deste artigo, as políticas industriais são retomadas com o lançamento da PICTE pelo Ministério do Desenvolvimento, Indústria e Comércio e com o PROFARMA pelo BNDES, visando o estímulo ao investimento privado na produção de farmoquímicos e medicamentos. Outro fato importante foi a criação da Agência Brasileira de Desenvolvimento Industrial (ABDI), no ano de 2004, órgão deliberativo, formado por representantes do governo federal e da sociedade civil, que ficou responsável pela execução das políticas industriais do governo brasileiro. Nesse mesmo ano, foi promulgada a "Lei de Inovação", com o objetivo de estimular a interação entre institutos de ciência e tecnologia (públicos) e os empresários em projetos de $P \& D$, mediante a permissão de remuneração e dedicação dos pesquisadores do serviço público e pela concessão de subvenção econômica, o que viria a acontecer, mais efetivamente, com a ampliação dos recursos orçamentários dos fundos setoriais, em 2007, do Fundo Nacional de Desenvolvimento Científico e Tecnológico (FNDCT), gerido pela FINEP. Destaca-se, ainda, a promulgação da chamada "Lei do Bem”, em 2005, que buscou promover o investimento privado em P\&D mediante isenção fiscal.

No que diz respeito especificamente à biotecnologia farmacêutica, houve avanços importantes no marco regulatório com a Lei de Biossegurança, de 2005, que estabeleceu as possibilidades e as limitações das pesquisas envolvendo organismos geneticamente modificados e com células-tronco. Além disso, em 2007, foi lançada a Política de Biotecnologia, que instituiu o Comitê Nacional de Biotecnologia, que além de tratar de questões éticas e de biossegurança, tratase de um órgão deliberativo sobre as políticas de desenvolvimento industrial, não só na área de saúde, como também na agropecuária, meio ambiente e aplicação industrial. 


\begin{tabular}{|c|c|c|c|}
\hline Evento & Legislação & Data & Resumo \\
\hline PITCE & n.d. & $31 / 03 / 04$ & Define o complexo industrial da saúde como área estratégica. \\
\hline BNDES/Profarma & n.a. & $01 / 04 / 04$ & $\begin{array}{l}\text { Financiamento de máquinas e equipamentos para a indústria } \\
\text { farmacêutica e depois para todo o CEIS. Em 2011, aprovada } \\
\text { nova linha para inovação e outra para biofármacos. }\end{array}$ \\
\hline Lei da inovação tecnológica & Lei N. ${ }^{\circ} 10.973$ & $02 / 12 / 04$ & Incentivos fiscais e subvenção econômica à P\&D. \\
\hline ABDI & Lei N. ${ }^{\circ} 11.080$ & $30 / 12 / 04$ & $\begin{array}{l}\text { Institui o serviço social autônomo com objetivo de executar as } \\
\text { políticas de desenvolvimento industrial. }\end{array}$ \\
\hline Lei do Bem & Lei N. ${ }^{\circ} 11.196$ & $21 / 11 / 05$ & $\begin{array}{l}\text { Incentivos fiscais à P\&D (REPES, RECAP e Programa Inclusão } \\
\text { Digital). }\end{array}$ \\
\hline Lei de Biossegurança & Lei N. ${ }^{\circ} 11.105$ & $23 / 11 / 05$ & $\begin{array}{l}\text { Regulamenta a pesquisa com organismos geneticamente } \\
\text { modificados e com células-tronco. }\end{array}$ \\
\hline Política de Biotecnologia & Decreto N. ${ }^{\circ} 6.041$ & $08 / 02 / 07$ & $\begin{array}{l}\text { Institui a Política de Desenvolvimento da Biotecnologia, cria o } \\
\text { Comitê Nacional de Biotecnologia, }\end{array}$ \\
\hline FNDCT & Lei N. ${ }^{\circ} 11.540$ & $12 / 11 / 07$ & $\begin{array}{l}\text { Amplia a dotação orçamentária do FNDCT, criado em } 1969 \text { e } \\
\text { reestabelecido em } 1991 .\end{array}$ \\
\hline GECIS & Decreto n. $^{\circ} 12$ & $12 / 05 / 08$ & $\begin{array}{l}\text { Cria, no âmbito do MS, o GECIS, com o objetivo de viabilizar } \\
\text { ambiente econômico e institucional ao desenvolvimento do CIS. }\end{array}$ \\
\hline Lista de produtos estratégicos & Portaria 978/GM/MS & $16 / 05 / 08$ & $\begin{array}{l}\text { Lista de medicamentos estratégicos do SUS, de interesse para o } \\
\text { desenvolvimento industrial. }\end{array}$ \\
\hline Lista de produtos estratégicos & Portaria N. ${ }^{\circ}$ 1.284/GM/MS & $26 / 05 / 10$ & $\begin{array}{l}\text { Atualiza a lista de medicamentos estratégicos do SUS, de } \\
\text { interesse para o desenvolvimento industrial. }\end{array}$ \\
\hline Lista de produtos estratégicos & Portaria N. ${ }^{\circ} 3.089 / \mathrm{GM} / \mathrm{MS}$ & $11 / 12 / 13$ & $\begin{array}{l}\text { Atualiza a lista de medicamentos estratégicos do SUS, de } \\
\text { interesse para o desenvolvimento industrial. }\end{array}$ \\
\hline PDP & Lei N. ${ }^{\circ} 11.774$ & $17 / 09 / 08$ & $\begin{array}{l}\text { Reforça CIS como área estratégica e inclui medicamentos } \\
\text { biotecnológicos como prioridades de desenvolvimento industrial. }\end{array}$ \\
\hline PDP (2) & Lei N. ${ }^{\circ} 11.786$ & 25/09/08 & $\begin{array}{l}\text { Reforça CIS como área estratégica e inclui medicamentos } \\
\text { biotecnológicos como prioridades de desenvolvimento industrial. }\end{array}$ \\
\hline Margem de preferência & Lei 12.349 & $15 / 12 / 10$ & $\begin{array}{l}\text { Estabelece margem de preferência de compras públicas para } \\
\text { empresas nacionais e que invistam em P\&D. }\end{array}$ \\
\hline PBM & Decreto 7.540 & $02 / 08 / 11$ & $\begin{array}{l}\text { Reforça o CIS e a transferência tecnológico como prioridades de } \\
\text { desenvolvimento industrial. }\end{array}$ \\
\hline PROCIS & Portaria N. ${ }^{\circ}$ 506/GM/MS & $21 / 03 / 12$ & $\begin{array}{l}\text { Programa de modernização de gestão, infraestrutura e apoio à } \\
\text { transferência tecnológica aos LFOs. }\end{array}$ \\
\hline Margem de preferência (2) & Decreto N..$^{\circ} 7.713$ & $03 / 04 / 12$ & $\begin{array}{l}\text { Estabelece a aplicação de margem de preferência nas licitações } \\
\text { realizadas no âmbito da Administração Pública Federal para } \\
\text { aquisição de fármacos e medicamentos. }\end{array}$ \\
\hline Dispensa de Licitação & Lei 12.715 & $17 / 09 / 12$ & $\begin{array}{l}\text { Dispensa de Licitação na compra de produtos ou serviços em que } \\
\text { há um processo de transferência de tecnologia de produtos } \\
\text { estratégicos para o SUS. }\end{array}$ \\
\hline PDPs / MS & Portaria N. ${ }^{\circ} 834$ GM/MS & $18 / 04 / 12$ & $\begin{array}{l}\text { Define as diretrizes e os critérios para o estabelecimento das } \\
\text { PDPs. }\end{array}$ \\
\hline FINEP/ Inova Saúde & n.a. & $11 / 04 / 13$ & $\begin{array}{l}\text { Programa de financiamento de projetos inovadores em } \\
\text { farmoquímicos, biofármacos e medicamentos. }\end{array}$ \\
\hline PDPs / MS (2) & Portaria N. ${ }^{\circ} 2.531$ GM/MS & $12 / 11 / 14$ & $\begin{array}{l}\text { Refine as diretrizes e os critérios para o estabelecimento das } \\
\text { PDPs. }\end{array}$ \\
\hline
\end{tabular}

Quadro 1: Legislação de política industrial nos anos 2000: Brasil, com especial referência à indústria farmacêutica.

Fonte: Elaboração própria. 
É a partir de 2008, no entanto, que há uma esforço mais concentrado no desenvolvimento produtivo do chamado CEIS, com a criação do GECIS, como parte da nova política industrial do governo federal, a Política de Desenvolvimento Produtivo (PDP), lançada nesse mesmo ano. O foco de ação do GECIS são os chamados produtos estratégicos do SUS, que envolvem os produtos médico-hospitalares mais utilizados no atendimento a população, àqueles associados às doenças tropicais (malária, dengue, etc.), e os de maior peso no orçamento, como os medicamentos oncológicos e os antirretrovirais. A lista de produtos estratégicos vem sendo atualizada periodicamente como pode ser visto no Quadro 1.

O ápice das ações governamentais, a fim de incentivar o desenvolvimento da indústria farmacêutica brasileira, são as PDPs, no âmbito do Ministério da Saúde, que, como mencionado, representam políticas de parcerias público-privada envolvendo transferência de tecnologia para empresas públicas e privadas nacionais. Essa política, no entanto, não exclui a participação dos LFM. O foco é incorporação de capacidade de produção de farmoquímicos e biofármacos de medicamentos considerados estratégicos para o SUS, a partir da transferência voluntária de tecnologia dos LFM.

A estratégia política das PDPs é articular a garantia de compra pelo Estado, dando preferência às empresas nacionais, públicas e privadas, resgatar o papel dos laboratórios públicos na produção de medicamentos essenciais ao SUS, financiar a modernização produtiva e criar incentivos, via subvenção econômica e outras permissões legais, à P\&D (MINISTÉRIO DA SAÚDE, 2014). Para viabilizar essa estratégia, uma das ações foi a criação do PROCIS, em 2012, um programa de modernização dos LFOs, que concedeu recursos financeiros a alguns laboratórios da rede oficial para melhorar suas capacidades produtivas, a fim de incorporar tecnologia externa. Houve ainda a criação de margens de preferência nas compras públicas para empresas inovadoras, isto é, que invistam em P\&D, com a Lei 12.349, de 2010, e margens de preferências para a aquisição de medicamentos de própria Administração Pública pelo Decreto 7.713 de 2012, isto é, até então, pela Lei 8.666, de 1993, os laboratórios da rede oficial tinham de participar de licitações para vender seus produtos ao SUS.

Além disso, Lei no 12.715, de 2012, tornou dispensável a licitação em compras de produtos estratégicos do SUS com transferência de tecnologia, o que permitiu flexibilização e uso do poder de compra do Estado para estimular a difusão de tecnologia para os laboratórios públicos (BRASIL, 2012c). O uso do poder de compra do Estado já fazia parte da política industrial desde 2004, quando se estabeleceu margem de preferência e dispensa de licitação nas compras das ICT envolvendo transferência tecnológica (BRASIL, 2004), reforçada em 2010, com o estabelecimento de margem de preferência para micro e pequenas empresas nacionais e empresas que realizem desenvolvimento tecnológico no país (BRASIL, 2010), mas foi ampliada no âmbito do SUS pelos decretos 7.713, para a compra de medicamentos estratégicos, e 7.767, para a compra de equipamentos e produtos médicos, ambos de 2012 (BRASIL, 2012a, b).

As Portarias N. ${ }^{\circ} 834$, de 2012, e 2.531, de 2014, estabeleceram as regras para as PDPS. Tais portarias visaram regulamentar o processo de contratação das PDPs e também dar maior transparência no processo de apresentação e seleção de projetos, dado o episódio de suspensão da PDP da Labogen, empresa investigada pela Polícia Federal e que supostamente envolvia um dos acusados na operação Lava Jato, Alberto Youssef (FOLHA, 2014a,b). Além disso, o mecanismo de produção, distribuição, comercialização e transferência de tecnologia, bem como a regressividade na formação dos preços foram estabelecidos na última Portaria, cuja lógica de funcionamento foi apresentada na segunda seção deste artigo.

Somados à oferta de crédito pelo BNDES (com as três edições do PROFARMA) e de subvenção econômica pela FINEP (incluindo o Inova Saúde, de 2013), o governo conseguiu articular uma série de modificações institucionais a fim de promover o desenvolvimento industrial farmacêutico no Brasil. Entre os incentivos e permissões criadas, destacam-se: a possibilidade de uso do poder de compra do Estado de maneira discricionária, o que não era plenamente possível com a Lei de Licitações de 1993, dispensando de licitação a compra de produtos estratégicos do SUS envolvendo transferência de tecnologia e da própria Administração Pública (direta ou indireta, 
contemplando os LFOs); crédito subsidiado e recursos não reembolsáveis para o investimento em P\&D em farmacêutica e biotecnologia; isenção fiscal e maior permissão de colaboração entre institutos públicos de ciência e tecnologia com empresas privadas; investimento público na modernização produtiva e organizacional dos LFOs, a fim de viabilizar a incorporação de tecnologia externa.

\section{Considerações finais}

As alterações institucionais mostradas acimas ilustram o esforço do governo federal nos últimos anos para tentar adotar uma política industrial discricionária, tarefa difícil desde a abertura comercial e a adesão à Organização Mundial do Comércio no início dos anos 1990. Diferentemente do período de industrialização por substituição de importações, levadas a cabo pelo governo brasileiro desde a década de 1930 até 1980, a margem de manobra para políticas discricionárias, principalmente direcionadas ao capital nacional, são muito estreitas. Embora deva se ressaltado que a política específica das PDPs não excluem as empresas estrangeiras em prol das nacionais, mas propõe um acordo do tipo ganha-ganha para todos os agentes envolvidos: por parte dos LFOs e LPNs, interessa adquirir o conhecimento tecnológico e vender o produto acabado ao SUS; por parte dos LFMs, interessa dar sobrevida aos produtos cujas patentes expiraram ou vão expirar, ou ainda, para aqueles que não atuam no Brasil é uma oportunidade de ingressar no mercado, sem falar no fato de que, enquanto não houver a transferência de tecnologia, serão estes os fornecedores de medicamentos ao SUS, sem concorrência em licitações, já que os parceiros públicos, os LFOs, serão os intermediários dispensados de licitação nessas parcerias público-privadas; por fim, por parte do Ministério da Saúde, interessa adquirir os produtos estratégicos a preços mais baixos do que os vigentes.

Trata-se de uma rara "coalização” orquestrada em uma política pública que, se bemsucedida, pode aumentar a eficiência dos gastos do SUS, ampliando a oferta dos produtos estratégicos à população, ao mesmo tempo que diminui o deficit comercial da indústria farmacêutica com a produção local. Além disso, representaria um avanço em termos de emprego e renda, gerados pelos LFOs e LPNs, bem como um aumento na capacidade tecnológica desses laboratórios, principalmente se conseguirem absorver a tecnologia de produção de medicamentos biológicos, de maior complexidade quando comparados aos medicamentos tradicionais de base química.

Porém, há de se destacar, como já mencionado na segunda seção, os riscos de inviabilidade dos investimentos e, mais do que isso, de incapacidade de absorção de tecnologia externa pelos laboratórios nacionais. As Portarias que regulamentam as PDPs não preveem nenhum tipo de sanção caso o processo de transferência de tecnologia não seja bem-sucedido, nem para os parceiros nacionais, nem para as empresas estrangeiras. Assim, corre-se o risco de que a capacitação tecnológica não ocorra e que os LFMs continuem com seu monopólio, usando os LFOs como “barrigas de aluguel”, isto é, como um caminho para burlar a "Lei de Licitações” e fugir, assim, da concorrência com outras empresas privadas.

Outro ponto de atenção é o fato das PDPs contemplarem apenas transferência tecnológica relacionada à produção. O sucesso das parcerias podem aumentar as receitas dos laboratórios nacionais, gerando recursos financeiros para expandir suas competências tecnológicas no futuro. Mas esse é apenas o primeiro passo de um projeto que requer mais tempo de maturação. Apenas com o reinvestimento em atividades de $\mathrm{P} \& \mathrm{D}$ com uma busca deliberada de capacitação tecnológica para inovar inovação pode assegurar um processo de catching up tecnológico. Caso contrário, a indústria farmacêutica brasileira tende a manter seu status quo, com a incorporação de produção de alguns farmoquímicos e biofármacos que podem se tornar obsoletos no futuro à medida que os LFMs consigam lançar medicamentos melhorados, mais eficazes ou substitutivos dos atuais.

Convém ressaltar que este artigo traz resultados preliminares de uma pesquisa ainda em curso, e muitos aspectos das mudanças institucionais e de seus efeitos, em termos de lograr os objetivos propostos pela política industrial, ainda estão em abertos. 


\section{Referências Bibliográficas}

BRASIL. Decreto de 12 de maio de 2008. Cria, no âmbito do Ministério da Saúde, o Grupo Executivo do Complexo Industrial da Saúde - GECIS, e dá outras providências. , 12 maio 2008. Disponível em: <http://www.planalto.gov.br/ccivil_03/_Ato2007-2010/2008/Dnn/Dnn11578.htm>. Acesso em: 6 mar. 2014.

BRASIL. Decreto $n^{0}$ 7.713, de 3 de abril de 2012. , 3 abr. 2012 a. Disponível em: <http://www.planalto.gov.br/ccivil_03/_Ato2011-2014/2012/Decreto/D7713.htm>. Acesso em: 6 mar. 2012.

BRASIL. Decreto $n^{0}$ 7.767, de 27 de junho de 2012. Estabelece a aplicação de margem de preferência em licitações realizadas no âmbito da administração pública federal para aquisição de produtos médicos para fins do disposto no art. $3^{\circ}$ da Lei ${ }^{0}$ 8.666, de 21 de junho de 1993. , 27 jun. 2012 b. Disponível em: <http://www.planalto.gov.br/ccivil_03/_Ato20112014/2012/Decreto/D7767.htm>. Acesso em: 6 mar. 2012.

BRASIL. Lei ${ }^{0} 10.973$, de 2 de dezembro de 2004. Dispõe sobre incentivos à inovação e à pesquisa científica e tecnológica no ambiente produtivo e dá outras providências. , 2 dez. 2004. Disponível em: <http://www.planalto.gov.br/ccivil_03/_ato2004-2006/2004/lei/110.973.htm>. Acesso em: 6 mar. 2014.

BRASIL. Lei ${ }^{0} 12.349$, de 15 de dezembro de 2010. Altera as Leis nos 8.666, de 21 de junho de 1993, 8.958, de 20 de dezembro de 1994, e 10.973, de 2 de dezembro de 2004; e revoga o § 1 o do art. 2o da Lei no 11.273, de 6 de fevereiro de 2006. , 15 dez. 2010. Disponível em:

<http://www.planalto.gov.br/ccivil_03/_Ato2007-2010/2010/Lei/L12349.htm>. Acesso em: 6 mar. 2014.

BRASIL. Lei $\mathrm{n}^{0}$ 12.715, de 17 de setembro de 2012. Altera a alíquota das contribuições previdenciárias sobre a folha de salários devidas pelas empresas que especifica; institui o Programa de Incentivo à Inovação Tecnológica e Adensamento da Cadeia Produtiva de Veículos Automotores, o Regime Especial de Tributação do Programa Nacional de Banda Larga para Implantação de Redes de Telecomunicações, o Regime Especial de Incentivo a Computadores para Uso Educacional, o Programa Nacional de Apoio à Atenção Oncológica e o Programa Nacional de Apoio à Atenção da Saúde da Pessoa com Deficiência; restabelece o Programa Um Computador por Aluno; altera o Programa de Apoio ao Desenvolvimento Tecnológico da Indústria de Semicondutores, instituído pela Lei no 11.484, de 31 de maio de 2007; altera as Leis nos 9.250, de 26 de dezembro de 1995, 11.033, de 21 de dezembro de 2004, 9.430, de 27 de dezembro de 1996, 10.865, de 30 de abril de 2004, 11.774, de 17 de setembro de 2008, 12.546, de 14 de dezembro de 2011, 11.484, de 31 de maio de 2007, 10.637, de 30 de dezembro de 2002, 11.196, de 21 de novembro de 2005, 10.406, de 10 de janeiro de 2002, 9.532, de 10 de dezembro de 1997, 12.431, de 24 de junho de 2011, 12.414, de 9 de junho de 2011, 8.666, de 21 de junho de 1993, 10.925, de 23 de julho de 2004, os DecretosLeis nos 1.455, de 7 de abril de 1976, 1.593, de 21 de dezembro de 1977, e a Medida Provisória no 2.199-14, de 24 de agosto de 2001; e dá outras providências. , 17 set. 2012 c. Disponível em: <http://www.planalto.gov.br/ccivil_03/_ato2011-2014/2012/lei/112715.htm>. Acesso em: 6 mar. 2014.

BRASIL. Ministério da Saúde. Portaria No 2.531, de 12 de novembro de 2014. Redefine as diretrizes e os critérios para a definição da lista de produtos estratégicos para o Sistema Único de Saúde (SUS) e o estabelecimento das Parcerias para o Desenvolvimento Produtivo (PDP) e disciplina os respectivos processos de submissão, instrução, decisão, transferência e absorção de tecnologia, aquisição de produtos estratégicos para o SUS no âmbito das PDP e o respectivo 
monitoramento e avaliação. Brasília. , 12 nov. 2014. Disponível em:

<http://bvsms.saude.gov.br/bvs/saudelegis/gm/2014/prt2531_12_11_2014.html>. Acesso em: 29 jun. 2016.

FINEP. Edital de seleção pública conjunta FINEP/MCTI/MS/CNPq de apoio à inovação tecnológica no setor de saúde - Inova Saúde - Biofármacos, farmoquímicos e medicamentos 03/2013. . [S.l.]: Finep. Disponível em:

$<$ http://download.finep.gov.br/chamadas/inova_saude/editais/EditalINOVASAUDE-Farmacos.pdf>. Acesso em: 6 mar. 2014. , 11 abr. 2013

FOLHA. Saúde cancela parceria com laboratório investigado pela PF - 27/06/2014 - Poder Folha de S.Paulo. Disponível em: <http://www1.folha.uol.com.br/poder/2014/06/1477791-saudecancela-parceria-com-laboratorio-investigado-pela-pf.shtml>. Acesso em: 8 jul. 2016a.

FOLHA. Após caso Labogen, Saúde deve definir critérios para escolha de laboratórios 04/07/2014 - Poder - Folha de S.Paulo. Disponível em:

<http://www1.folha.uol.com.br/poder/2014/07/1481011-apos-caso-labogen-saude-deve-definircriterios-para-escolha-de-laboratorio.shtml>. Acesso em: 8 jul. $2016 \mathrm{~b}$.

GADELHA, C. A. G. A dinâmica do sistema produtivo da saúde: inovação e complexo econômicoindustrial. Rio de Janeiro: Editora FIOCRUZ, 2012.

GADELHA, C. A. G. Inovação e complexo industrial da saúde. . São Paulo: [s.n.]. Disponível em: <http://www.ipd-farma.org.br/uploads/paginas/file/palestras/7_enifarmed/10h00-

Carlos\%20Gadelha-7o\%20Enifarmed.pdf>. Acesso em: 6 mar. 2014. , 20 ago. 2013

HODGSON, G. M. What are institutions. Journal of Economic Issues, v. XL, n. 1, p. 1-25, mar. 2006.

MINISTÉRIO DA CIÊNCIA, TECNOLOGIA E INOVAÇÃO. Estratégia nacional de ciência, tecnologia e inovação 2012-2015: balanço das atividades estruturantes 2011. . [S.l.]: MCTI. Disponível em: <http://www.mct.gov.br/upd_blob/0218/218981.pdf>. Acesso em: 6 mar. 2014. , 2012

MINISTÉRIO DA SAÚDE. Gastos do SUS. Brasília: [s.n.]. , 7 out. 2009

MINISTÉRIO DA SAÚDE. Parceria para o Desenvolvimento Produtivo (PDP). Disponível em: $<$ http://portalsaude.saude.gov.br/index.php/o-ministerio/principal/leia-mais-o-ministerio/581-sctieraiz/deciis/l2-deciis/12090-parceria-para-o-desenvolvimento-produtivo-pdp>. Acesso em: 21 nov. 2014.

MINISTÉRIO DA SAÚDE. Portaria $n^{0} 506$ de 21 de março de 212. Institui o Programa para o Desenvolvimento do Complexo Industrial da Saúde (PROCIS) e seu Comitê Gestor. , 21 mar. 2012. Disponível em: <http://bvsms.saude.gov.br/bvs/saudelegis/gm/2012/prt0506_21_03_2012.html>. Acesso em: 6 mar. 2012.

NORTH, D. C. Institutions, institutional change and economic performance. Cambridge, MA: Cambridge University Press, 1990.

PIERONI, J. P. O papel do BNDES no desenvolvimento do complexo industrial da saúde. . Rio de Janeiro: [s.n.]. Disponível em:

<http://www.firjan.org.br/data/pages/2C908CEC442B6391014446AD7F0D5144.htm>. Acesso em: 19 fev. 2014. , 31 jan. 2014 